\title{
FENTANYL VERSUS MAGNESIUM SULPHATE AS ADJUVANT TO HYPERBARIC BUPIVACAINE IN SPINAL ANESTHESIA FOR ELECTIVE CESAREAN SECTIONS
}

\author{
Ashraf Said Sayed Ahmed, Kamelia Ahmed Abaza, Dina abdel Hameed El Sadek \\ Depatment of anaesthesia and surgical intesive care, Zagazig University, Al-sharkia, Egypt
}

\begin{abstract}
Background: Subarachnoid block achieved a wide spread popularity as a simple and effective method of anesthesia for elective cesarean sections. The use of intrathecal adjuvants has gained popularity, with the intention of reducing the dose of local anesthetics, maintaining hemodynamic stability and delaying the onset of pain during the postoperative period The present study compared between fentanyl and magnesium sulphate as adjuvant to hyperbaric bupivcaine in subarachnoid block for patients undergoing elective cesarean sections.

Subject and Methods: A total of 56 consented pregnant females undergoing elective cesarean sections, ASA grade I and II, were randomized into two groups of 28 patients each. Group F received $12.5 \mathrm{mg}$ of intrathecal $0.5 \%$ hyperbaric bupivacaine $(2.5 \mathrm{ml})+12.5 \mu \mathrm{g}(0.25 \mathrm{~mL})$ fentanyl $+.75 \mathrm{ml}$ normal saline, Group M $12.5 \mathrm{mg}$ of intrathecal $0.5 \%$ hyperbaric bupivacaine $(2.5 \mathrm{ml})+100$ $\mathrm{mg}(1 \mathrm{ml})$ magnesium sulfate. The two groups were assessed for character of the block, haemodynamic changes, duration of post operative analgesia, the side effects.

Results: The onset of both sensory and motor block was slower in the magnesium group. The duration of spinal anesthesia and motor block were significantly longer in the magnesium group. Total analgesic dose requirement was less in Group M. Hemodynamic parameters were comparable in the two groups. Intrathecal magnesium caused minimal side effects.

Conclusion: The addition of magnesium sulfate $100 \mathrm{mg}$ to bupivacaine for sub-arachnoid block in patients undergoing elective cesarean section prolongs the duration of analgesia and reduces postoperative analgesic requirements without additional side effects and adverse neonatal outcomes.

Key words: Subarachnoid block, magnesium sulfate, fentanyl, post operative analgesia, elective cesarean sections.

Corresponding Author: Amany Fathy Metwaly, fathyamany89@yahoo.com, 01005865315
\end{abstract}

\section{INTRODUCTION}

Qubarachnoid block achieved a wide spread $\checkmark$ popularity as a simple and effective method of anesthesia for elective cesarean sections ${ }^{(1)}$. Among the local anesthetics, $0.5 \%$ hyperbaric bupivacaine is the most commonly used drug for subarachnoid block; however, the most important disadvantage of the single injection is its limited duration ${ }^{(2)}$. In recent years, the use of intrathecal adjuvants has gained popularity, with the intention of reducing the dose of local anesthetics, maintaining hemodynamic stability, delaying the onset of pain during the postoperative period, and thus reducing the demand for postoperative rescue analgesics. Addition of adjuvants ensures faster recovery, enabling patients to return to their routine activity more quickly ${ }^{(3)}$. Fentanyl being highly lipid soluble diffuses into the spinal cord and binds to dorsal horn receptors rapidly when administered intrathecally. This produces a rapid onset of analgesia with minimal cephalic spread $^{(4)}$. With the discovery of the N-methylD-aspartate (NMDA) receptors and its links to nociceptive pain transmission and central sensitization, there has been interest in utilizing noncompetitive NMDA receptor antagonists, such as ketamine, magnesium sulfate, and dextromethorphan, as potential analgesic agents (5). Magnesium sulfate has analgesic properties, primarily related to the regulation of calcium influx into cells and antagonism of N-methyl$\mathrm{D}$-aspartate receptors in the central nervous system (6). Intrathecal magnesium sulfate increases the duration of analgesia without increasing side effects. Intrathecal magnesium sulfate has been found to be safe and effective 
as an adjuvant to hyperbaric bupivacaine in parturients for labor analgesia ${ }^{(7)}$.

\section{SUBJECT AND METHODS}

This double blind randomized controlled clinical trial had been carried out in obstetric department in Zagazig university hospitals, during the period between May and December 2017 after obtaining Institutional Review Board (IRB) approval and informed written consent from the patients.

-Inclusion criteria: pregnant females who are scheduled for elective cesarean sections under spinal anesthesia with: age: $21-35$ years old, physical status : ASA II.

-Exclusion criteria: Patients refusal, patients with known history of allergy to study drugs, patients not able to understand pain assessment test, morbid obesity, patients with thrombocytopenia or coagulopathy, advanced liver, renal and cardiac diseases, fetal distress. Methods: - patients were randomly allocated to two groups:

Group F : patients received $12.5 \mathrm{mg}$ of intrathecal $0.5 \%$ hyperbaric bupivacaine $(2.5 \mathrm{ml})+12.5 \mu \mathrm{g}(0.25$ $\mathrm{ml})$ fentanyl $+0.75 \mathrm{ml}$ normal saline. Group M : patients received $12.5 \mathrm{mg}$ of intrathecal $0.5 \%$ hyperbaric bupivacaine (2.5 $\mathrm{ml})+100 \mathrm{mg}(1 \mathrm{ml})$ magnesium sulfate.

- In the operating room, venous access was secured on the non dominant hand of every patient using $18 \mathrm{G} / 20 \mathrm{G}$ cannula. All patients was received a $10 \mathrm{ml} / \mathrm{kg}$ intravenous (i.v.) preload of lactated Ringer before spinal anesthesia.

- Base line parameters including heart rate (HR), systolic blood pressure (SBP), diastolic blood pressure (DBP), mean blood pressure (MAP), respiratory rate (RR) and $\mathrm{O}_{2}$ saturation $\left(\mathrm{SPO}_{2}\right)$ was recorded. These were again recorded immediately after establishment of the block and then every $5 \mathrm{~min}$ for the first $20 \mathrm{~min}$ and every $10 \mathrm{~min}$ until the end of the surgery.

-Technique of lumber puncture:

Setting position was used then identification of anatomic land marks was done. The best interspace was identified with a finger nail imprint. Infiltration of local anesthetic was done then a 25-gauge Quincke needle was used for spinal block. The midline technique was used. The medication was injected slowly at a rate of $1 \mathrm{ml}$ every 5 seconds. The needle was withdrawn and the patient was immediately turned supine with left uterine displacement using a wedge under the right hip.

-Sensory block was assessed every minute by pinprick in the mid clavicular line until a stable level of block was achieved. The duration of sensory block was defined as the time from intrathecal injection to regression of the sensory block to $\mathrm{T} 12$.

-Motor block was assessed using a modified Bromage score ${ }^{(8)}(0=$ no motor loss, $1=$ inability to flex hip, $2=$ inability to flex hip and knee, 3 = inability to flex hip, knee and ankle). The duration of motor block was defined as the time from intrathecal injection to the score reach zero. The duration of spinal analgesia was defined as the period from the spinal injection to the time of administration of first rescue analgesic for pain in the postoperative period. -During procedure any bradycardia (HR under 50 beats/min) or tachycardia (HR over 110 beats/ min) and any hypotension (MAP levels lower than $60 \mathrm{mmHg}$ ) or hypertension (MAP value of over $150 \mathrm{mmHg}$ ) was observed, recorded and treated. Requirement of ephedrine or atropine in both the groups was recorded. The incidence of side effects such as sedation and pruritus was noted and recorded. Pruritus was graded as $0=$ none, $1=$ mild, and $2=$ severe ${ }^{(7)}$. Sedation was measured using the modified Ramsey Sedation Score ${ }^{(9)}$ as $1=$ anxious, restless, 2 = cooperative, oriented, tranquil, $3=$ responds to commands only, $4=$ brisk response to light glabellar tap or loud noise, $5=$ sluggish response to light glabellar tap or loud noise and $6=$ no response. The incidence of nausea and vomiting was noted and recorded during surgery and postoperative. Nausea and vomiting was graded as $0=$ no nausea or vomiting, $1=$ nausea without vomiting, 2 = both nausea and vomiting present and $3=$ more than 2 episodes of 
vomiting in $30 \mathrm{~min}{ }^{(7)}$. Intravenous ondansetron was given as rescue medication for vomiting.

-Neonatal outcome was assessed by Apgar score ${ }^{(10)}$ at 1 and $5 \mathrm{~min}$, and the need for neonatal mask ventilation and tracheal intubation by a pediatrician. Pain was assessed using a visual analogue scale (VAS) ${ }^{(11)}$ from 0 to $10(0=$ no pain; $10=$ maximum imaginable pain) "after explanation of the procedure to the patients" every $15 \mathrm{~min}$ after the block until the end of the surgery and 2, 4, 8, 12, $24 \mathrm{~h}$ postoperatively.

-Time for first request for analgesia and the total amount of resque analgesia was noted and recorded. Postoperatively, intramuscular diclofenac $75 \mathrm{mg}$ was given for rescue analgesia whenever the pain score is $>3$. If pain scores is more than 3 even after two doses of diclofenac, then intravenous nalbuphine hydrochloride 10-20 mg was added. Overall patient satisfaction with anesthesia and analgesia was scored at 24 hours as $1=$ excellent; $2=\operatorname{good}$ and $3=$ bad $^{(7)}$.

\section{Statistical analysis:}

The results obtained in the study are presented in a tabulated manner and analyzed using Microsoft Excel and SPSS software. The haemodynamic variables were represented by mean value \pm SD. The statistical significance in mean difference was performed using analysis of variance (ANOVA) and Chi square test as appropriate. A $P$ value of $<0.05$ was considered significant and $<0.001$ as highly significant.

\section{RESULTS}

Of the total of 56 patients, 28 patients in each group were evaluated and compared. The two groups were comparable with respect to the demographic and operational factors. No significant differences were found among them with respect to age, sex, weight, time between the total of 34 patients, 17 patients in each group were evaluated and compared. The two groups were comparable with respect to the demographic and operational factors. No significant differences were found among them with respect to age, sex, weight, time between fentanyl group and magnesium sulfate group. There were no statistically significant differences between the two groups regarding systolic, diastolic and mean blood pressure all over the studied times.

There was a significant delay in onset of sensory blockade in group M $(4.4 \pm 0.44 \mathrm{~min})$ as compared to group F $(2.9 \pm 0.28 \mathrm{~min})$. The time to reach maximum extent of cephaled spread was Longer in group $\mathrm{M}(8.3 \pm 0.32 \mathrm{~min})$ compared with $(5.1 \pm 0.24 \mathrm{~min})$ in group $\mathrm{F}$; this was statistically highly significant $(\mathrm{P}<0.001)$. The highest sensory level achieved was similar in both groups. This was statistically insignificant ( $\mathrm{P}$ value $>0.05)$. The duration of sensory block was Longer in group $\mathrm{M}$ (247.2 $\pm 8.17 \mathrm{~min})$ compared with $(205.7 \pm 3.06$ min) in group F; this was statistically highly significant $(\mathrm{P}<0.001)$

There was a significant delay in onset of motor blockade in group $\mathrm{M}(6.47 \pm 0.42 \mathrm{~min})$ as compared to group $\mathrm{F}(5.2 \pm 0.25 \mathrm{~min})$. The time of maximum degree of motor block was significantly delayed for group $\mathrm{M}$ as compared to group $\mathrm{S}$. It was $(9.4 \pm 0.40 \mathrm{~min})$ in group $\mathrm{M}$ and $(8.8 \pm 0.24 \mathrm{~min})$ in group $\mathrm{F}$ and these results were statistically significant $(\mathrm{P}$ value $<0.001)$. The duration of sensory block was Longer in group $M(226.8 \pm 2.59 \mathrm{~min})$ compared with $(189.2 \pm 3.5 \mathrm{~min})$ in group $\mathrm{F}$; this was statistically highly significant $(\mathrm{P}<0.001)$.Time taken for two segments regression was longer in group M (95.35 \pm 2.77 min) compared with $(84 \pm 1.38 \mathrm{~min})$ in group $\mathrm{F}$; this was statistically highly significant $(\mathrm{P}<0.001)$.

VAS scores in the first $24 \mathrm{~h}$ were significantly lower in magnesium group than in the fentanyl. Magnesium group significant late for request analgesic as mean time in magnesium group was $312.82 \pm 5.04$ while in fentanyl group was 271.8 \pm 6.08 and with significant lower dose as $75 \%$ of fentanyl group took 3 ampoule while $0 \%$ in magnesium group took 3 ampoule and only 21.4 took 2 ampoule. There was no significant differences between the two groups regarding nausea, vomiting, 
pruritis or other neurological complications. Magnesium group significantly associated with higher satisfaction as $78.6 \%$ of them were excellent satisfaction while only $35.7 \%$ were excellent satisfaction and the rest were good. There was no significant differences between the two groups regarding APGAR score of the new born at one and five minutes after delivery.

\section{DISSUCION}

In this study we compared the effect of intrathecal bupivacaine - fentanyl and bupivacine - magnesium sulfate regarding achievement of adequate intraoperative analgesia, prolongation of the duration of postoperative analgesia and thus reducing the demand for postoperative rescue analgesics. Also the groups were compared regard: Time of onset, highest level of sensory block, time of onset, highest level of motor block, duration of motor block, presence of sedation, cardiovascular complications as hypotension, bradycardia, presence of side effects as nausea, vomiting, shivering, and pruritis, postoperative pain, using visual analogue scale. This study had shown that there was a delayed onset of sensory and motor block in group $\mathrm{M}$ compared with group $\mathrm{F}$ and the time to reach maximum extent of cephaled spread was longer in group M compared with the group F. Ozalevli et al. (2005) ${ }^{(12)}$ and Malleswaran et al. (2010) ${ }^{(13)}$ have postulated the changes in $\mathrm{pH}$ and baricity of local anesthetic solution with the addition of $\mathrm{Mg}$ as the cause of delayed onset of block.

This study agreed with Arora, et al. ( $2015)^{(7)}$ which found that the time to reach maximum block height $(5.3 \pm 0.5$ min vs. $8.7 \pm$ $0.5 \mathrm{~min})$ and the onset of motor block $(5 \pm 1$ min vs. $6 \pm 1 \mathrm{~min}$ ) were significantly slower in Group $M$ than in the Group F.

The duration of sensory block was Longer in group M (247.2 \pm 8.17 min) compared with $(205.7 \pm 3.06 \mathrm{~min})$ in group $\mathrm{F}$; this was statistically highly significant $(\mathrm{P}<0.001)$.This correlates well with the study conducted by Khalili et al. $(2011)^{(14)}$ who found that the addition of $100 \mathrm{mg} \mathrm{MgSO}_{(4)}$ to $15 \mathrm{mg}$ bupivacaine without opioid supplement, prolonged the duration of the sensory block and decreased postoperative analgesic consumption.

Sensory block has been found to be increased with the use of $\mathrm{Mg}$, mechanism postulated being its action as calcium channel as well as NMDA receptors antagonists. In humans, calcium channel antagonists, mediate anti-nociception by its action of decreasing calcium mediated release of neurotransmitter implicated in nociception and inflammation. Blocking of NMDA receptors has been implicated with a decrease in post nociception central sensitization of pain.

This study found that the highest dermatomal level of sensory block was $\mathrm{T}_{4}$ in group $\mathrm{M}$ compared with $\mathrm{T}_{4}$ in group $\mathrm{F}$ and this was statistically insignificant.

This result agreed with Arora, et al. $(2015)^{(7)}$ who found that there was no significant differences between both groups in the maximum level of sensory block it was $T_{4-6}$ in group $\mathrm{M}$ and $\mathrm{T}_{4-6}$ in group $\mathrm{F}$. Also Katiyar, et al. $(2015)^{(15)}$ had the same results.

The onset and resolution of motor blockade and the time to attain maximum motor degree in the present study were longer in the magnesium group. Though hyperbaric bupivacaine was used in our study, Ozalevli et al. $(2005)^{(12)}$ observed a similar delay in onset of spinal anesthesia when adding intrathecal magnesium to isobaric bupivacaine. Arcioni et al. $(2007)^{(16)}$ also observed that intrathecal and epidural magnesium sulfate potentiated and prolonged motor block.

Regarding the duration of spinal analgesia, first time to require analgesia and total analgesic requiremets; group $\mathrm{M}$ show significantly longer time than group $\mathrm{F}$.

Malleeswaran, et al. (2010) $)^{(13)}$ observed that addition of intrathecal magnesium sulfate to bupivacaine-fentanyl anesthesia prolonged the duration of analgesia, which was found to be significant. Arcioni, et al. $(2007)^{(16)}$ also observed that intrathecal and epidural magnesium sulfate potentiated and prolonged motor block. Chaudhary, et al. (2016) ${ }^{(17)}$ observed that motor block duration and the 
duration of analgesia in the $100 \mathrm{mg}$ magnesium sulfate group were significantly prolonged.

We noticed that VAS scores in the first 24 hours postoperative were significantly lower in magnesium group than in the fentanyl. Magnesium group was significant late for request analgesic and with significant lower dose of rescue analgesics in magnesium group. Similar reductions in analgesic requirements have been reported by Marzouk, et al. (2003) ${ }^{(18)}$ who studied the effect of three different doses of intrathecal magnesium.

This study has shown that there was no significant difference between $\mathrm{Mg}$ group and control group as regards hemodynamic stability (heart rate, systolic and diastolic blood pressure and oxygen saturation) in intra-operative and postoperative periods.

Studies in which intrathecal magnesium was given to various different groups of patients found that none had symptoms suggestive of neurotoxicity (Shoebi G, 2007) ${ }^{(19)}$ , nor did they exhibit signs of systemic toxicity such as hypotension, arrhythmias, somnolence or weakness, during the study.

The intrathecal dose of $100 \mathrm{mg}$ magnesium sulphate that we used in the study was comparable to that of the study by Arcioni, et al. (2007) ${ }^{(16)}$ and Khalili, et al. (2011) ${ }^{(14)}$ who found that larger doses decreased postoperative analgesic requirement without inducing adverse reactions.

These results indicate that in order for total analgesic consumption to be reduced, higher doses of magnesium sulphate are required, similar to the dose used in the study by Arcioni, et al. $(2007)^{(16)}$.

\section{CONCLUSION}

Addition of magnesium sulfate has more advantages as intrathecal adjuvant to bupivacaine than other agents as it leads to more prolongation of sensory and motor block with less side effects and more postoperative analgesia reduce postoperative analgesic requirements.

\section{REFERENCES}

1. Cousins M.J., Bridenbaugh P.O., Carr D.B., and Horlocker T.T. :Neural Blockade in Clinical Anesthesia and Pain Medicine. Lippincott Williams \& Wilkins, Philadelphia, Pa, USA, 4th edition. 2008; chapter 1: 5-20. 2. Mohsin M.D., Saket K.:Observation on analgesic efficacy of intrathecal clonidine as an adjuvant to hyperbaric bupivacaine in patients undergoing lower limb surgeries. International Journal of Contemporary Medical Research. 2016; 3: 1640-1643.

3. Shukla D., Verma A., Agarwal A., Pandey H.D., Tyagi C.: Comparative study of intrathecal dexmedetomidine with intrathecal magnesium sulphate used as adjuvants to bupivacaine. J Anaesthesiol Clin Pharmacol. 2011; 27: 495-499. 4.Katiyar S., Dwivedi C., Tipu S., Jain R.K.: Comparison of different doses of magnesium sulphate and fentanyl as adjuvants to bupivacaine for infraumbilical surgeries under subarachnoid block. Indian J Anaesth. 2015; 59: 471-475.

5.Chaudhary S.K., Verma R.K., Rana S.:Magnesium sulfate at two different doses as an adjuvant to bupivacaine in infraumblical (below knee) orthopedic surgeries under spinal anesthesia. Ains Shams J Anaesth. 2016; 9: 416-421.

6. Kroin J.S., McCarthy R.J., Von Roenn N.:Magnesium sulphate potentiates morphine antinociception at the spinal level. Anesth Analg. 2000; 90: 913-917.

7. Arora B., Pathak D.G., Tarat A., Sutradhar D., Nath R., Sheokand B.: Comparison of intrathecal magnesium sulphate and fentanyl as adjuvants to hyperbaric bupivacaine in preecclamptic parturients undergoing elective cesarian section. J Obstet Anaesth Crit Care. 2015; 5: 9-15.

8.Graham A.C., McClure J.H.:Quantitative assessment of motor block in laboring women receiving epidural analgesia. Anaesthesia J. 2001; 56: 470-476 .

9.Marino, Paul L., Kenneth M. Sutin, and Paul L. Marino: The little ICU Book of Facts 
And Formulas. Philadelphia:Wolter Kluwer Health Lippincott Williams, Wilkins. 2009; chapter 9: 460-465. 10. Carlo W.A., Kliegman R.M., Stanton B.F., St. Geme J.F. III, Schor N.F., Behrman R.E., eds.: Nelson Textbook of Pediatrics. Philadelphia, PA: Elsevier Saunders, 19th edition. 2011; chap 88: 2220-2230. 11. Bodian C.A., Freedman G., Hossain S., Eisenkraft J.B., Beilin Y.: The visual Analog Scale for Pain : clinical significance in Postoprative Patients. Anesthiology J. 2001; 95: 1356-1361 .

12.Ozalevli M, Cetin TO, Unlugenc H, et al.: The effect of adding intrathecal magnesium sulphate to bupivacaine fentanyl spinal anaesthesia. Acta Anaesthesiol Scand. 2005; 49: 1514-1519.

13. Malleeswaran S, Panda N, Mathew P, et al.: Magnesium as an intrathecal adjuvant in mild pre-ecclempsia. Int J Obstet Anesth. 2010; 19: 161-166.

14. Khalili G, Janghorbani M, Sajedi P, et al.: Effects of adjunct intrathecal magnesium sulfate to bupivacaine for spinal anesthesia: A randomized, double-blind trial in patients undergoing lower extremity surgery. J Anesth. 2011; 25: 892-897.
15.Katiyar S, Dwivedi C, Tipu S, et al: Comparison of different doses of magnesium sulphate and fentanyl as adjuvants to bupivacaine for infraumbilical surgeries under subarachnoid block. Indian J Anaesth. 2015; 59: 471-475.

16. Arcioni R, Palmisoni S, Tigano S, et al.: Combined intrathecal and epidural magnesium sulfate supplementation of spinal anesthesia to reduce post-operative analgesic requirements: a prospective, randomized, double-blind, controlled trial in patients undergoing major orthopedic surgery. Acta Anaesthesiol Scand. 2007; 51: 482-489.

17. Chaudhary SK, Verma RK, Rana S, et al.: Magnesium sulfate at two different doses as an adjuvant to bupivacaine in infraumblical (below knee) orthopedic surgeries under spinal anesthesia. Ains Shams J Anaesth. 2016; 9: 416-421.

18. Marzouk S, El-Hady NA, Lotfy M, et al.: The effect of three different doses of intrathecal magnesium sulphate on spinal opioid analgesia. Eg J Anaesth. 2003; 19: 405-409.

19. Shoebi G, Sadegi M, Firazian A, et al.: The additional effect of magnesium to lidocaine in spinal anaesthesia for caesarean section. Int $\mathbf{J}$ Pharmacol. 2007; 3: 425-427. 